\title{
CUESTIONES FILOLÓGICAS SOBRE LA HISTORIA ECLESIÁSTICA INDIANA DE FRAY JERÓNIMO DE MENDIETA
}

\author{
Esther Hernández \\ Instituto de la Lengua española, CSIC, Madrid
}

El manuscrito de la Historia Eclesiástica Indiana ${ }^{1}$ ha permanecido oculto a la historia durante casi tres siglos, si bien el contenido de la obra se conoció en su momento. Como es bien sabido, la Relación de Mendieta fue parcialmente traducida al latín por Fr. Francisco Gonzaga ${ }^{2}$ y la Historia copiada casi de manera íntegra por Fr. Juan de Torquemada en su Monarquía indiana ${ }^{3}$. De hecho, la obra que el franciscano fray Jerónimo de Mendieta, escribió a finales del siglo XVI, no vio la luz hasta que, en 1870, la editó J. García Icazbalceta ${ }^{4}$.

Naturalmente, García Icazbalceta realizó una transcripción del texto conforme a la puntuación, acentuación y otros aspectos propios de la lengua de su tiempo. Su edición — valiosa y muy respetable — ha sido la base

${ }^{1}$ Fr. Jerónimo de Mendieta, Historia Eclesiástica Indiana, ed. J. García Icazbalceta [en adelante, $H E I]$.

${ }^{2}$ Mendieta estuvo escribiendo la Relación hasta 1575. En ella dejaba constancia de la actuación de los franciscanos en la Nueva España. Sin embargo, esta obra quedó sin concluir, en parte porque Mendieta amplió su proyecto y decidió escribir la Historia, en la que se propuso no ya una simple descripción, sino una verdadera historia. La Relación la tradujo al latín años más tarde Fr. Francisco de Gonzaga. Esta primera obra de Mendieta fue concluida por Fr. Pedro de Oroz y Fr. Francisco Suárez en 1585, pero no se publicó hasta que lo hizo Fr. Fidel de Jesús Chauvet en 1947.

${ }^{3}$ Fr. Juan de Torquemada, Los veinte y un libros y Monarchia Indiana con el origen $y$ las guerras de las Indias Occidentales, 1615.

${ }^{4} \mathrm{~V}$. HEI, p. XXIII. 
textual de las ediciones sucesivas que se han realizado de la crónica ${ }^{5}$. En esta ocasión, me propongo plantear una serie de cuestiones filológicas para valorar la conveniencia de una nueva edición de la HEI, que siga el único manuscrito original conservado, hoy en la Universidad de Texas en Austin.

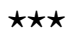

La Historia Eclesiástica Indiana es una fuente primera, con un material documental imprescindible para conocer la actuación social, política, religiosa - y también lingüística - de la orden franciscana en México durante el siglo XVI. Mendieta recibió la orden de redactar tal obra por ser un buen conocedor de la circunstancia histórica de los doce primeros franciscanos y de otros miembros de la Orden, dado que vivió en México la práctica totalidad de su vida como misionero, sin estar más de dos años seguidos en el mismo lugar.

Además de historiador, también fue un hombre comprometido con las cuestiones de política eclesiástica, un auténtico programador político, como demuestran las numerosas cartas y documentos diversos que escribe al rey y a las autoridades peninsulares y de la Nueva España ${ }^{6}$.

\section{Problemas De tRANSMisión}

Mendieta no consiguió ver impresa su obra, por razones que no conocemos. Quizás fueran razones de contenido (por sus duras críticas contra los españoles) las que le negaron el «favor» de las autoridades o tal vez solo ocurrió que el discípulo al que le encargó tarea de imprimirla no puso el empeño debido en agilizar los trámites para su impresión o no pudo hacerlo ${ }^{7}$.

${ }^{5}$ Vid. referencias bibliográficas.

${ }^{6}$ La producción escrita de Mendieta es extraordinaria, tanto en la introducción de J. García Icazbalceta como en el estudio de F. Solano, podemos encontrar información sobre la vida y la obra de este autor, así como información histórica sobre otros cronistas con los que tuvo trato directo, como Motolinía, Sahagún, Andrés de Olmos o Acosta.

${ }^{7}$ F. Solano señala que no existe documentación de que hubiera un impedimento legal para su impresión, de lo que suele quedar constancia en los archivos de la 
Lo cierto es que, no pudiendo encargarse personalmente de su publicación - ya que debió de concluirla casi al tiempo de su muerte en 1604-, Mendieta le dejó encargado a su discípulo fray Juan Bautista todo el asunto administrativo de la publicación (avales, licencias eclesiásticas y civiles). Este mismo es quien proporciona tal información en el Prólogo del Sermonario mexicano de 1607, donde confiesa:

escribió Mendieta en lengua castellana un gran libro que intituló Historia Eclesiástica Indiana, el cual antes de que muriese me lo entregó para que yo lo imprimiese y hase mejorado en haber caído en manos del P. Fray Juan de Torquemada, que no le dará menos vida y espíritu... del que dio al libro de la Vida y milagros del Beato fray Sebastián de Aparicio, que imprimió en años pasados

Torquemada, lejos de llevar a cabo el encargo, copió la Historia en su Monarquía indiana, que vio la luz en 1615. Sobre este plagio se ha escrito bastante $\mathrm{y}$, sin duda, la percepción histórica de este hecho puede ser de lo más diversa. El mismo Icazbalceta se encargó de cotejar ambas obras, para lo que elaboró la «Tabla de correspondencias» que acompaña todas las ediciones o reimpresiones de la Historia.

El manuscrito en el que se basó Icazbalceta para la primera edición de 1870 le llegó de España. Parece que, a principios del siglo Xvi, había llegado la HEI al convento de San Francisco de Vitoria. En su momento, el guardián fray Juan de Domayquia intentó que se imprimiera, pero no hubo suerte. Consta que le hizo una introducción, un prólogo en 1611 y una dedicatoria.

Cabe plantearse si hubo realmente dos manuscritos de la Historia. Icazbalceta asegura que en el que utiliza «toda la letra del volumen es muy clara y pequeña, aunque de diversas manos: se conoce que fue copiado con esmero, y corregido después» (pág. xxvi). Además, afirma que «tiene señal de faltar cinco hojas» (íd.), que corresponderían al prólogo general de la obra. Según las palabras de Icazbalceta, se deduce que se trataría más bien de una copia, lo cual no es extraño ya que era un procedimiento habitual en la época duplicar los originales sobre todo por temor a extravío. Esto conviene tenerlo presente a la hora de valorar si es

Inquisición. Por ello, me inclino a pensar que pudo tratarse más bien de negligencia. A nadie sorprende, ni siquiera hoy, que una obra esté en prensa durante uno o varios años. Entre tanto, pudo suceder cualquier contingencia material. 
la mano de Mendieta la que escribe el manuscrito o la mano de varios de sus contemporáneos, cuando menos para sacar conclusiones de tipo lingüístico.

Por tanto, la versión primera de la HEI pasaría de Mendieta a Bautista y éste, a su vez, le haría llegar presumiblemente el mismo texto a Torquemada. Ahora bien, ¿la que utilizó Torquemada es la que llegó a Vitoria? Lo cierto es que, a no ser que apareciese otro manuscrito, es difícil contestar a esta pregunta. De lo que no cabe duda es de que la versión anotada por fray Juan Domayquia en 1611 es la que Icazbalceta adquirió y editó, la misma que hoy está depositada en Austin.

He presentado este resumen de las vicisitudes por las que ha pasado el texto, entre otras razones, porque, en el estudio preliminar de la edición de F. Solano, éste atribuye su mala fortuna a que la Monarquía de Torquemada era «una obra con un léxico más en consonancia con el gusto barroco de la época, y tratando ambas del mismo contenido de la Orden franciscana, siempre con problemas económicos, se orientaría hacia la necesidad de ofrecer una obra moderna antes que otra que estaba escrita con un léxico desfasado» (pág. lxxxv). Es decir, F. Solano da un argumento de tipo lingüístico para lo que él llama la impublicación de la Historia.

Creo que las consideraciones lingüísticas del excelente estudio de Solano sobre la Historia (págs. lxxiv-lxxvi) merecen ser objeto de revisión pero, para acometer un estudio sistemático de la lengua del texto, sería preferible que dispusiéramos de una edición más cercana al manuscrito. La edición de Icazbalceta, con las limitaciones de una puntuación, una acentuación y un estilo decimonónico, no impide la transmisión del contenido, pero sí que conozcamos la forma real en que estaba escrita la crónica.

\section{SOBRe LA EDICIÓN DE ICAZBALCETA}

En general, hay una gran consistencia en la modernización de las grafias de la edición de Icazbalceta, lo que naturalmente facilita la lectura. No obstante, he detectado algún desliz gráfico, que reiteran las sucesivas ediciones. Así, llaman la atención las siguientes grafías, que contrastan con la normalización general del texto: 
cada doce o quince iglezuelas o templillos (lib. II, cap. vii).

zurujanos con las medicinas (lib.II, cap. xxvi).

persecusiones (lib. IV, cap. xlii)

silicio (lib.V, cap. $\mathrm{x}$ )

azañas (lib. II, cap. vi),

alhombras (lib. IV, cap. xii)

cama más blanda que una corcha o estera (lib. V, cap. v).

Icazbalceta copió literalmente: chapitel (lib. II, cap. xviii); poquella (lib. II, cap. xviii); Hebrero (lib. IV, cap. xxix). Tales grafias de tipo arcaizante son perfectamente normales en textos del siglo $\mathrm{XvI}^{8}$; de hecho, la ortografia no estaba fijada en el grado que a veces puede pensarse. Por otra parte, hay dificultades en la comprensión de algunos pasajes que presentan anomalías de tipo gramatical, que evidencian un error de lectura.

Así, en:

donde pudieran habitar seis tantos indios de los que él traía consigo (lib. I, cap. xiii).

Posiblemente haya en vez de la palabra tantos, la palabra cientos.

Son formas antiguas sintácticas las contracciones dello, della, pero su uso no resulta arcaico en México a fines del siglo xvi. Lo mismo sucede con el vocabulario que selecciona Solano (abarrisco, abolorios, etc.). Son palabras que documentamos en textos no sólo americanos, sino también españoles coetáneos; otra cosa muy diferente es que no sean propias de la lengua literaria. Es evidente que, una crónica como la de Mendieta y una obra literaria, tienen por fuerza un tipo de discurso diferente, pues pertenecen a registros distintos. Considero, más bien, que se trata de un texto representativo del habla de la época, y en particular su léxico - que he analizado con cierto detalle. En él, destaca el componente americano como discrepante del habla peninsular.

\section{EL COMPONENTE INDOAMERICANO}

Precisamente, en las palabras de origen americano, tenemos la suerte de que Icazbalceta sigue un criterio editorial diferente pues dice:

${ }^{8}$ Cf. C. Company Company, 1994. 
en los nombres mexicanos he seguido enteramente la ortografía del manuscrito, aunque varia y por lo común errónea.

He analizado las palabras americanas contenidas en la $H E I$ y hay que señalar, en primer lugar, que los antillanismos empleados son un fiel reflejo de la lengua novohispana del xvi. Se trata de palabras que se encuentran en todo tipo de documentos indianos (aji, areito, aura, bejuco, bohique, cacique, caimán, canoa, caribe, cazabe, cutara, embijar, macana, maguey, maíz, manglar, piragua, tabaco y tuna $)^{9}$. Como es lógico, todas ellas están perfectamente integradas a la fonética española y, salvo las palabras especialmente frecuentes como cacique (con 66 apariciones en el texto) o maiz, suelen estar definidas, mediante diversos procedimientos. Así, Mendieta utiliza apoyo sinonímico, con una voz patrimonial coordinada a la indígena:

cantaban sus bailes $o$ areitos (lib. I, cap. vii)

canoas o barcos (lib. I, cap. xiii)

cutaras o sandalias (lib. II, cap. xxxix)

caimanes o lagartos grandes (lib. II, cap. xli)

Lo habitual es que defina la palabra con un comentario metalingüístico del tipo «que llaman»:

los bohiques, que eran los señores (lib. I, cap. vii)

ají o pimiento, que es la común especia de todos sus manjares (lib. II, cap. xxxix)

tiraron de ella con sogas recias que llaman de bejucos (lib. I, cap. vii)

manglares, cierto género de árboles que se hacen por aquellas partes (lib. I, cap. xiii)

cazabe, que es el pan de la tierra hecho de raíces (lib. I, cap. xvi)

en una penca de maguey, que es el cardón de donde sacan la miel (lib. II, cap. xix)

tunas, que en Castilla llaman higos de las Indias (lib. II, cap. xxx)

macanas, que son unos palos anchos de encina que les sirven de espadas o porras (lib. V, cap. i)

ciertas aves carniceras, llamadas auras (lib. V, cap. i)

no se embijasen, que es teñirse el cuerpo de negro o de otros colores (lib. V, cap. vii)

${ }^{9}$ Cf. P. Boyd-Bowman, 1972. 
En el caso de los nombres propios de origen nahua, hay que señalar que aparecen algunos nombres con mayúscula y otros en minúscula sin razón aparente, salvo que debían estar así en el original. Este hecho me lleva a interpretar que todo el texto, y no sólo el componente indígena, presenta esta variación gráfica.

Por ejemplo, hay nombres de dioses o ídolos, como «Tlacatecolotl, persona de búho o hombre que tiene gesto de parecer de búho» (lib. II, cap. xii); o, nombres de fiestas, como «la mayor fiesta del año que llamaban Panquezaliztli» (lib. II, cap. xvii). Los nombres propios y los topónimos, como es natural, no están adaptados al español fonéticamente.

El resto de los préstamos nahuas presenta diversidad en cuanto a su integración. No son muchos los que están totalmente integrados. Se trata de las voces: aguacate, copal, capulies, chile, macehuales, mecapal (mecapalejos), nahuas, petaca.

Todos, salvo tameme, están definidos:

no podrían llevar sus mercadurías de unas partes a otras tan ligeramente como con los tamemes (lib. IV, cap. xxix)

copal o ánime (lib. II, cap. xviii)

capulies que son cerezas de la tierra (lib. V, cap. xxi)

árbol que llaman aguacate (lib. V, cap. lii)

recio cordel, que llaman mecapal (lib. II, cap. xx)

vasallos populares de los que se llaman macehuales (lib. III, cap. lvii).

Solo presenta vacilación formal petaca, que en ocasiones aparece con forma nahua:

en una caja de caña, que ellos llaman petlacalli (lib. V, cap. v).

Este grupo de aztequismos debía formar parte del vocabulario novohispano, pues los documentamos en textos de la época ${ }^{10}$. El resto presenta una forma extranjera en la edición; Mendieta transcribe palabras o frases del náhuatl y, a continuación, proporciona el equivalente castellano. Algunos han tenido éxito en su paso al español, aunque en la HEI tengan aún forma indígena, por ejemplo: «maxtli, que es como toca de camino» (lib. II, cap. xviii) [en textos contemporáneos encontramos masta-

${ }^{10}$ Por ejemplo, en el Vocabulario en lengua castellana y mexicana de fray Alonso de Molina (1571); vid. E. Hernández, 1994, 1996. 
te]; «cierta goma, que llamaban ulli» (lib. II, cap. xix) [adaptado al castellano como hule]; «chalchihuitl, que es especie de esmeralda» (lib. II, cap. $\mathrm{Xxv}$ ) [chalchihuite].

Para terminar con el léxico, sólo mencionaré algunos americanismos que se documentan en el texto:

le dieron con unas porras en la cabeza (lib. I, cap. $\mathrm{x}$ ) = en otros lugares, $m a-$ canas

dábanles con él de la pimienta de la tierra, y unas raíces como nabos, asadas (lib. I, cap. xvi) = aji o chile, batata o el camote.

la leche de cardo (lib. II, cap. i) = maguey

pieles de adives (lib. II, cap. ix) $=$ coyotes

atabales y bailes (lib. II, cap. xvii) $=$ areitos, mitotes

cerezas de la tierra (lib. III, cap. $\mathrm{xxx}$ ) = capulies

higos de las Indias (lib. III, cap. $\mathrm{xxx}$ ) = tunas

manzanillas silvestres de la tierra (lib. III, cap. xxx), etc.

\section{Criterios provisionales para la edición de la HEI}

La edición de Icazbalceta respeta la mayor parte de los aspectos gramaticales y léxicos, pero la normalización ortográfica borra cualquier huella del componente dialectal del texto.

Parece lógico que, desde el punto de vista del lingüista, se vea como necesidad la lectura y la transmisión editorial de la crónica del modo más fiel posible al manuscrito, con el fin de que a continuación se pueda estudiar el estado de la lengua española en aquel momento y lugar ${ }^{11}$. Para un filólogo cualquier detalle formal tiene o puede tener un significado.

Lo ideal sería que se pudiera realizar una transcripción lo más ajustada al texto original, pero esto tiene una serie de inconvenientes reales, pues imprimir paleográficamente es muy complicado aunque existan o se puedan establecer convenciones. De todas formas, no creo que sea estrictamente necesaria la rigurosidad formal llevada hasta sus últimas consecuencias Para eso creo que pueden servir otros medios técnicos, como la fotografia digital. Sin embargo, en el otro extremo, si modernizamos el manuscrito perdemos la validez lingüística del corpus. 
Por ello, con el fin de que una edición de una crónica, como la de Mendieta, tenga hoy una validez interdisciplinar, voy a tratar algunos problemas con los que me he encontrado ${ }^{12}$ y a proponer unos criterios en cierta medida eclécticos.

En primer lugar, en cuanto a las abreviaturas, como suelen reiterarse, las relacionaría y explicaría en el estudio. Las abreviaturas poseen escaso significado lingüístico. Por ello, soy partidaria de que se desarrollen, dejando las que puedan ser casos especiales, marcadas en el texto con cursiva o ángulos, con la tipografía más ligera posible.

En segundo lugar, no veo problema en respetar las grafias del manuscrito, pues cualquier grafía puede tener interés fonético u ortográfico, aunque lo haría con siguientes salvedades:

a) en el caso de los distintos tipos de representación de $s$ (la sigma, la $s$ alta), sí habría que unificar, aunque anotando la peculiaridad de sus usos en el estudio.

b) en el caso de la $R$ en forma de lira ${ }^{13}$, sería conveniente representar la vibrante múltiple, también explicándolo en el lugar adecuado.

c) unificaría las grafias de la vocal, como $j, \gamma, i$.

En tercer lugar, creo que en un texto extenso como es el de la Historia de Mendieta, convendría modernizar la puntuación y la acentuación según el uso actual, ya que ambas intervenciones pueden contribuir a agilizar la lectura. Soy partidaria de intervenir también en la transcripción de las mayúsculas y las minúsculas, cuyo uso en aquella época es muy inestable. Estos usos se pueden perfectamente referir en la introducción.

En cuarto lugar, trataría de homogeneizar la separación de palabras según el texto en su integridad. No creo que se dificulte la lectura si se mantienen determinados conglomerados muy habituales en la época (estrotro, deste, etc.) y mantener la separación de palabras según está en el original tiene un interés para la historia de la ortografía del español.

En fin, estas consideraciones prácticas son perfectamente debatibles, revisables y, sin duda, mejorables dependiendo del corpus.

${ }^{12}$ En concreto, voy a basarme en una de las cartas escritas de mano de Mendieta que he encontrado en el Instituto Valencia de don Juan de Madrid

${ }^{13}$ En la carta autógrafa que manejamos utiliza esa grafía. 


\section{REFERENCIAS BIBLIOGRÁFICAS}

Bautista, Fr. J., Sermonario en lengua mexicana, México, 1607.

Boyd-Bowman, P., Léxico hispanoamericano del siglo XVI, Londres, Tamesis, 1972. Company Company, C., Documentos Lingüísticos de la Nueva España. Altiplano Central, México, El Colegio de México, 1994.

Hernández, E., Estudios sobre el léxico en el "Vocabulario en lengua castellana y mexicana y mexicana y castellana» (1571) de fray Alonso de Molina, Ann Arbor, Michigan, 1994 (DAI: Dissertation Abstracts International [54:10, 3729A DAI No.: DA9408879] [SUNY at Albany]).

- «Vocabulario en lengua castellana y mexicana» de fray Alonso de Molina. Estudio de los indigenismos léxicos y registro de voces españolas internas, Madrid, CSIC, 1996.

Frago Gracia, J. A., "Criterio filológico y edición de textos indianos: sobre documentos de la Nueva España», Romance Philology, 53, 1999, págs. 119-135.

Mendieta, Fr. G. de, Historia Eclesiástica Indiana, Obra escrita a fines del siglo XVI, ed. Joaquín García Icazbalceta, México, Antigua Librería, 1870.

- Historia Eclesiástica Indiana. Con algunas advertencias de Fr. Joan de Domayquia, ed. de J. García Icazbalceta, México, Editorial Chávez Hayhoe, 1945.

- Historia Eclesiástica Indiana, estudio preliminar y edición de Francisco Solano y Pérez-Lila, Madrid, Atlas, 1973, 2 tomos, [Biblioteca de Autores Españoles, 260 y 261].

- Historia Eclesiástica Indiana, México, Porrúa, 1971, [reimpr. 1980], tercera edición facsimilar y primera con la reproducción de los dibujos originales del códice.

- Religiones, orden de San Francisco. Cosas para proueer. El orden que se podría tener para la buena prouisión delos frailes de san Francisco que passan a las Indias y residen en ellas... San Francisco de Vitoria, 6 de noviembre de 1571, Madrid, Instituto Valencia de don Juan, sign. envío 25, documentos 488-499 (495).

- Los nombres delos frailes de San Francisco que [estaban] quedaban al principio deste año de 1570. En la provinçia de mexico que se llama del santo evangelio y sus calidades son los siguientes..., Vitoria, 20 de noviembre de 1570, Madrid, Instituto Valencia de don Juan, sign. envío 25, documentos 488-499 (493).

Nueva colección de Documentos para la Historia de México, publicada por Joaquín García Icazbalceta: Códice Mendieta, Documentos franciscanos, Siglos XVI y XVII, t. II, México, Imprenta de Francisco Díaz de León, 1892; Cartas de Religiosos de la Nueva España, 1539-1594, México, 1886, [Kraus Reprint, Nendeln/ Liechtenstein, 1971]; Códice franciscano, Siglo XVI. Informe de la Provincia del Santo Evangelio al visitador Juan de Ovando, Informe de la Provincia de Guadalajara al mismo, Cartas de religiosos, 1533-1569, México, 1899 [Kraus Reprint, Nendeln/ Liechtenstein, 1971]. 
Oroz, Fr. P., Mendieta, Fr. G. de, y SuÁrez, Fr. F., Relación de la descripción de la Provincia del Santo Evangelio que es en las Indias Occidentales que llaman la Nueva España (1585). Introducción y notas de Fr. Fidel de Jesús Chauvet, hijo de la dicha Provincia, Nueva edición, México, 1975.

Torquemada, J. de, Los veinte y un libros y Monarchia Indiana con el origen y las guerras de las Indias Occidentales, Sevilla, 1615, ed. de León Portilla, México, 1964.

Vocabulario en lengua castellana y mexicana de fray Alonso de Molina, edición facsímil y estudio de Esther Hernández, Madrid, Agencia Española de Cooperación Internacional/ Biblioteca Nacional, 2001. 
